\title{
Phototherapy-Induced Covalent Binding of Bilirubin to Serum Albumin
}

\author{
GIULIO JORI, ELIANA ROSSI, AND FIRMINO F. RUBALTELLI ${ }^{(17)}$ \\ Department of Pediatrics and C. N. R. Center for the Physiology and Biochemistry of Hemocyanins and Other \\ Metallo-Proteins, Institute of Animal Biology, University of Padova, Padova, Italy
}

\begin{abstract}
Summary
Bilirubin displays a detectable fluorescence emission only when it is complexed with serum albumin, whereas free bilirubin has a very low fluorescence yield. Actually, nearly complete disappearance of bilirubin emission was obtained when the unirradiated human serum albumin-bilirubin complex was precipitated with acetone to extract the pigment; complete removal of protein-bound bilirubin (as monitored by fluorescence spectroscopy) was achieved by repeating the acetone extraction after incubation of the complex in the phosphate buffer, pH 7.4, containing $7 \mathrm{M}$ guanidinium chloride; the latter compound causes on extensive unfolding of protein molecules. On the other hand, in the case of irradiated solutions, even after denaturation of the protein with $7 \mathrm{M}$ guanidinium chloride, a detectable amount of bilirubin-type fluorescent material was found to be associated with albumin. This finding clearly shows that bilirubin and/or some photoproduct underwent in part a photoinduced covalent binding with human serum albumin. Fragmentation of the bovine albumin polypeptide chain according to the procedure detailed in the experimental section yielded only one peptide-containing material fluorescent in the $\mathbf{5 3 0}$ $\mathrm{nm}$ region. This fact underlines the selective nature of the photobinding reaction. The amino acid composition of the isolated peptide is shown in Table 2; the composition is closely similar with that found for peptide 187-397 of native bovine serum albumin. In the case of the jaundiced babies who were subjected to phototherapy, we were able to demonstrate that only after 7 to $9 \mathrm{hr}$ of exposure to light a detectable amount of bilirubin-type fluorescent material was present even at the end of the serum treatment with acetone and guanidinium chloride (see Fig. 1; Table 1). Fractional precipitation of the serum proteins by addition of controlled amounts of ammonium sulphate showed that the fluorescent matrial was present only in the albumin fraction. The photoadduct disappeared about 15 to 20 days after the phototherapy had been discontinued. This period of time represents the natural turnover period of human serum albumin.
\end{abstract}

\section{Speculation}

The demonstration of the in vivo occurrence of photodamage (the albumin-pigment photoadduct) stresses the importance of avoiding overexposure of patients to the light sources. Further studies are needed to define the phototherapy dose-effect relationship and to find out the treatment schedule, if any, sufficient to form photobilirubin and at the same time avoid photooxidation products. In addition, because the formation of the bilirubin-albumin covalent photoadduct is characterized by a high degree of spatial selectivity, it appears reasonable to hypothesize that this photochemical approach can be used to identify the high-affinity bilirubin-binding site on the albumin molecule.

Present evidence shows that both human (HSA) and bovine (BSA) serum albumin protect bound bilirubin from in vitro pho- todegradation (15). Such a protection is due to a competition between bilirubin and some amino acid side chains of the protein for the photooxidizing agent(s). After visible light irradiation of a 1:1 HSA-bilirubin complex, histidyl residues were preferentially affected with a consequent decrease of the binding capacity of the proteins, although the latter largely maintained its native tertiary structure. After prolonged irradiation, a decrease in tryptophan and tyrosine content was also observed, and HSA and BSA derivatives were largely denatured. In addition, bilirubin and/or some of its photoproducts were not completely removed from albumin even after extensive denaturation of the irradiated protein, suggesting that irradiation induced in part the formation of a bilirubin-albumin covalent photoadduct (15).

The present study was undertaken to characterize the photoaddition process observed in vitro more in detail, as well as to investigate whether the same photoprocess occurs also in vivo as a consequence of the phototherapy of jaundiced newborns.

\section{MATERIALS AND METHODS}

\section{MATERIALS}

BSA and HSA serum albumin crystallized and lyophilized, Fraction V were purchased from Sigma Chemical Co., St. Louis, MO; concentrations were estimated spectrophotometrically assuming extinction values at $279 \mathrm{~nm}$ of 6.67 and 5.30 for $1 \%$ solutions of BSA and HSA, respectively (6). Because defatting the proteins with charcoal in acid solution (3) had no appreciable effect on the photooxidation process, the commercial preparations were used as such. Bilirubin (Sigma Chemical Co.) was shown by thin-layer chromatography (12) to be essentially constituted by the IX $\alpha$ isomer, and its concentration was determined using a molar absorptivity value of 46,500 at $459 \mathrm{~nm}$ (15). Guanidine hydrochloride (Merck) was recrystallized once from absolute ethanol, and fresh solutions of this compound were prepared daily. Bilirubin and bilirubin-protein complexes were prepared by dissolving the dye in a few drops of $0.1 \mathrm{M} \mathrm{NaOH}$ and by adding the desired amount of buffer or of a protein solutions in $0.5 \mathrm{M}$

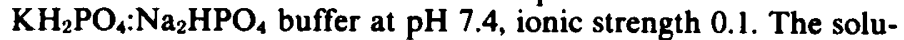
tions were maintained in the dark and used within a few hr. Final solutions to be irradiated were $0.1 \mathrm{mM}$ in both albumin and bilirubin, and absorption spectral studies showed that bilirubin solutions strictly followed Beer's law, suggesting that the dye was present essentially in a monomeric form. Under these conditions, bilirubin is essentially all bound at the single high-affinity site of HSA and BSA (7). In all cases, the dark controls were recovered unchanged within the period of time necessary for the irradiation experiments.

\section{IRRADIATION PROCEDURE}

Light from a stabilized 1250 watt high-pressure halogen lamp (Osram) was focused by a parabolic reflector on a l-cm-thick quartz cuvette containing $3 \mathrm{ml}$ of an air-equilibrated or degassed 
aqueous solution of the sample to be irradiated. A freshly prepared acetone filter was placed in the front of the irradiation cuvette to eliminate all wavelengths below $330 \mathrm{~nm}$. The irradiance in the 440 to $470 \mathrm{~nm}$ region, as measured with a thermopile, was about $300 \mu \mathrm{watts} / \mathrm{cm}^{2} / \mathrm{nm}$. The temperature of the solutions was maintained at $19 \pm 1^{\circ} \mathrm{C}$ by means of thermostated water circulating through the cell holder. In kinetic experiments, aliquots were taken at suitable intervals for spectroscopic and other analytical measurements.

\section{SPECTROSCOPIC MEASUREMENTS}

Absorption spectra were monitored at room temperature by a Perkin-Elmer 576 spectrophotometer using matched quartz cuvettes with an optical path of either 10 or $1 \mathrm{~mm}$. Absorbance measurements at specific wavelengths were obtained with a Zeiss M4/Q III single-beam spectrophotometer. Fluorescence emission spectra were recorded by a Perkin-Elmer MPF4 spectrophotofluorimeter, equipped with a 150 watt $X e$ light source and a R446F photomultiplier tube. Quartz cuvettes with an optical path of $10 \mathrm{~mm}$ were used, and the light emission was read at $90^{\circ}$ to the incident beam. The temperature of the analyzed solutions could be controlled to $\pm 0.5^{\circ} \mathrm{C}$ by circulating water; in all cases, the samples were kept at the desired temperature for about $10 \mathrm{~min}$ before measurement to ensure the attainment of thermal equilibrium. The optical density of the various samples was always lower than 0.15 at the excitation wavelength to minimize artifacts due to inner filter or self-absorption effects. Finally, the spectra were corrected for any fluorescence arising from the solvent system used. On the other hand, no corrections were applied for the wavelength-dependence of the light source emission and detector response.

\section{PRECIPITATION METHOD}

The HSA-bilirubin complex was precipitated from the aqueous solution or from the serum through the addition of acetone in a five-fold excess $(v / v)$ over water.

After $5 \mathrm{~min}$ centrifugation at $4000 \mathrm{rpm}$, the precipitate was redissolved in $0.5 \mathrm{M}$ phosphate buffer solution, $\mathrm{pH} 7.4$, containing $7 \mathrm{M}$ guanidinium chloride and then reprecipitated with acetone. Fluorescence excitation and emission spectra were carried out on the supernatants and on the final precipitate which was taken up with $0.5 \mathrm{M}$ phosphate buffer at $\mathrm{pH} 7.4$

\section{ISOLATION OF A BILIRUBIN-CONTAINING PEPTIDE}

The BSA-bilirubin complex (100 mg) after $30 \mathrm{~min}$ of exposure to light was treated with cyanogen bromide according to the procedure of King and Spencer (9) and then chromatographed on a Sephadex G-75 column $(35 \times 1.2 \mathrm{~cm})$ using $30 \%$ acetic acid as the eluant. Two fragments were obtained, named fragment $\mathrm{N}$ and C, which correspond with the peptide 1-186 and 187-545, respectively, of BSA.

Fluorescence analysis showed that only fragment $\mathrm{C}$ contained bound bilirubin.

Fragment $C$ was further treated with dithiotreitol in a 60:1 molar excess over the peptide, according to literature methods (6, 9).

Sephadex G-75 chromatography of the desalted and lyophilized reaction mixture gave an elution profile closely similar with that found by King and Spencer (9) after degradation of native BSA.
The bilirubin fluorescence was associated only with the portion of the eluate corresponding with the 187-397 segment of the albumin polypeptide chain.

This fragment was hydrolyzed by heating at $110^{\circ} \mathrm{C}$ for $22 \mathrm{hr}$ within evacuated sealed vials in the presence of $6 \mathrm{M} \mathrm{HCl}$. The solvent was then removed by lyophilization, and the dried samples were chromatographed on a Beckman $120 \mathrm{C}$ amino acid analyzer following the method of Moore and Stein (13).

\section{PATIENTS}

The subjects of this study were 29 healthy newborn infants who developed a nonhemolytic hyperbilirubinemia with $72 \mathrm{hr}$ of life (Table 1).

The phototherapy unit used in this study were multipledirection phototherapy apparatuses supplied with four special blue lamps (F20T12/BB), two of which were attached above and two below a transparent gauze cradle (14).

The intensity of the irradiation was $22 \mu$ watts $/ \mathrm{cm}^{2} / \mathrm{nm}$ within the wavelength range of 440 to $470 \mathrm{~nm}$ (measured with the BiliMeter; Olympic Medical Corp., Seattle, WA). Continuous phototherapy was initiated when the serum bilirubin level, determined by a Photo-Ictometer (O'Hara \& Co., Ltd., Tokyo) or by the Malloy-Evelyn method, had reached at least $10 \mathrm{mg} / \mathrm{dl}$ and discontinued when the serum bilirubin level had decreased to $8 \mathrm{mg}$ / dl. All the newborns were naked except for a blindfold when exposed to light.

Blood samples, used to investigate the albumin-bilirubin photoadduct, were the same as used for bilirubin determination. Bilirubin levels were determined every $6 \mathrm{hr}$ but in some cases even every $3 \mathrm{hr}$.

Blood samples obtained after having discontinued the light treatment were withdrawn every wk after having obtained informed consent from the parents.

\section{SERA ANALYSIS}

The sera of patients before, during, and after phototherapy were studied by the precipitation method used in the analysis of HSAand BSA-bilirubin complex. The presence of bilirubin in the samples analyzed was monitored by fluorescence emission $\left(\lambda_{\text {ex }}=\right.$ $460 \mathrm{~nm})$ and excitation $\left(\lambda_{\mathrm{em}}=530 \mathrm{~nm}\right)$ spectroscopy. The presence of the photoadduct was also studied in the sera after fractional precipitation with ammonium sulphate.

\section{RESULTS}

\section{IN VITRO STUDIES}

Bilirubin displays a detectable fluorescence emission only when it is complexed with serum albumin, whereas free bilirubin has a very low fluorescence yield (4). Actually, nearly complete disappearance of bilirubin emission was obtained when the unirradiated HSA-bilirubin complex was precipitated with acetone to extract the pigment; complete removal of protein-bound bilirubin (as monitored by fluorescence spectroscopy) was achieved by repeating the acetone extraction after incubation of the complex in the phosphate buffer, $\mathrm{pH} 7.4$, containing $7 \mathrm{M}$ guanidinium chloride. The latter compound causes an extensive unfolding of protein molecules.

On the other hand, in the case of irradiated solutions, even after denaturation of the protein with $7 \mathrm{M}$ guanidinium chloride, a

Table 1. Clinical data on 29 study infants ${ }^{1}$

\begin{tabular}{cccccccc}
\hline No. & Wt $(\mathrm{g})$ & $\begin{array}{c}\text { Gestational age } \\
(\mathrm{wk})\end{array}$ & $\begin{array}{c}\text { Apgar } \\
\text { score }\end{array}$ & $\begin{array}{c}\text { Bilirubin level at } \\
\text { start of photother- } \\
\text { apy (mg/dl) }\end{array}$ & $\begin{array}{c}\text { Flux ( } \mu \mathrm{l} / \mathrm{watt}_{\mathrm{wm}} \mathrm{cm}^{2} / \\
\mathrm{nm})\end{array}$ & $\begin{array}{c}\text { Average irradiation time } \\
\text { for appearance of the } \\
\text { photoadduct (hr) }\end{array}$ & $\begin{array}{c}\text { Average time for the } \\
\text { disappearance of the } \\
\text { photoadduct (days) }\end{array}$ \\
\hline 29 & 2730 & 38,3 & 8 & 14.1 & 22 & $7-9$ & $15-20$ \\
& $2000-4200$ & $36-41$ & $7-10$ & $11-18$ & & 78 \\
\hline
\end{tabular}

\footnotetext{
${ }^{1}$ Means and ranges.
} 
detectable amount of bilirubin-type fluorescent material was found to be associated with albumin. This finding clearly shows that bilirubin and/or some photoproducts underwent in part a photoinduced covalent binding with HSA.

At present, no quantitative estimation of the yield of the photobinding process is possible because the chemical nature of the photobound fluorescent bilirubin derivatives is unknown. However, on a qualitative basis, we observed an increase of the fluorescence yield as a function of the irradiation time, as well as a higher yield of fluorescent material when the irradiation was performed in deoxygenated solutions.

Previous studies on the irradiation of protein-dye complexes showed that photobinding processes are generally restricted within the dye-binding site (8). In actuality, fragmentation of the bovine albumin polypeptide chain according to the procedure detailed in the experimental section allowed us to isolate only one peptidecontaining material fluorescent in the $530 \mathrm{~nm}$ region. This fact underlines the selective nature of the photobinding reaction. The amino acid analysis of the isolated peptide is shown in Table 2;

Table 2. Amino acid analysis of the bilirubin-containing peptide isolated from the irradiated bilirubin-albumin complex

\begin{tabular}{lcc}
\hline \multicolumn{1}{c}{ Amino acid } & $\begin{array}{c}\text { Residues per molecular } \\
w t=25,000\end{array}$ & $\begin{array}{c}\text { Theory for peptide } \\
187-397\end{array}$ \\
\hline Lysine & 19.7 & 21 \\
Histidine & 3.2 & 5 \\
Arginine & 12.8 & 12 \\
Aspartic acid & 18.2 & 20 \\
Threonine & 11.3 & 11 \\
Serine & 12.2 & 12 \\
Glutamic acid & 27.4 & 29 \\
Proline & 8.0 & 9 \\
Glycine & 5.7 & 6 \\
Alanine & 16.2 & 17 \\
Valine & 14.5 & 14 \\
Isoleucine & 4.2 & 5 \\
Leucine & 19.5 & 21 \\
Tyrosine & 6.2 & 7 \\
Phenylalanine & 9.4 & 7 \\
Methionine & 0.3 & 0 \\
\hline
\end{tabular}

the composition is closely similar with that found for peptide 187 387 of native BSA (9).

\section{IN VIVO STUDIES}

In Figure 1, we show the fluorescence excitation spectrum (monitored at $530 \mathrm{~nm}$ ) of sera of jaundiced newborns before light treatment; the shape of the spectrum is coincident with that found for albumin-bound bilirubin. Clearly, acetone-treatment (see "Materials and Methods") removes a substantial fraction of the fluorescent material. Moreover, no residual bilirubin was associated with albumin after incubation of the serum with $7 \mathrm{M}$ guanidinium chloride. In all cases, the purity of the protein fraction was checked by monitoring the intrinsic fluorescence emission of the tryptophyl residues $\left(\lambda_{\mathrm{ex}}=290 \mathrm{~nm}\right.$; emission, $\left.\lambda_{\max }=348 \mathrm{~nm}\right)$. In the case of the same jaundiced babies who were subjected to phototherapy, we were able to demonstrate that only after 7 to 9 $\mathrm{hr}$ of exposure to light a detectable amount of bilirubin-type fluorescent material was present even at the end of the serum treatment with acetone and guanidinium chloride (Fig. 1; Table 1). In a few cases, newborns were irradiated with a regular phototherapy unit set up with eight white fluorescent lamps; the appearance of the photoadduct in the sera was observed only after at least $24 \mathrm{hr}$ of continuous phototreatment.

Fractional precipitation of the serum proteins by addition of controlled amounts of ammonium sulphate showed that the fluorescent material was present only in the albumin fraction. As shown in Table 1 , the photoadduct disappeared about 15 to 20 days after the phototherapy had been discontinued. This period of time represents the natural turnover period of HSA.

\section{DISCUSSION}

The data presented in this paper definitely demonstrate that visible light irradiation of the complex between both BSA or HSA and bilirubin causes the formation of a protein-pigment covalent photoadduct. At the present stage of our investigations, it cannot be decided whether the photobinding involves bilirubin or one of its photoproducts [e.g., a photoisomer (10)]. Several evidences support our conclusion, e.g., the lack of removal of bilirubin even from extensively denatured albumin only after irradiation and the isolation of a single bilirubin-containing peptide after fragmentation of the irradiated bilirubin-albumin complex. Inasmuch as the

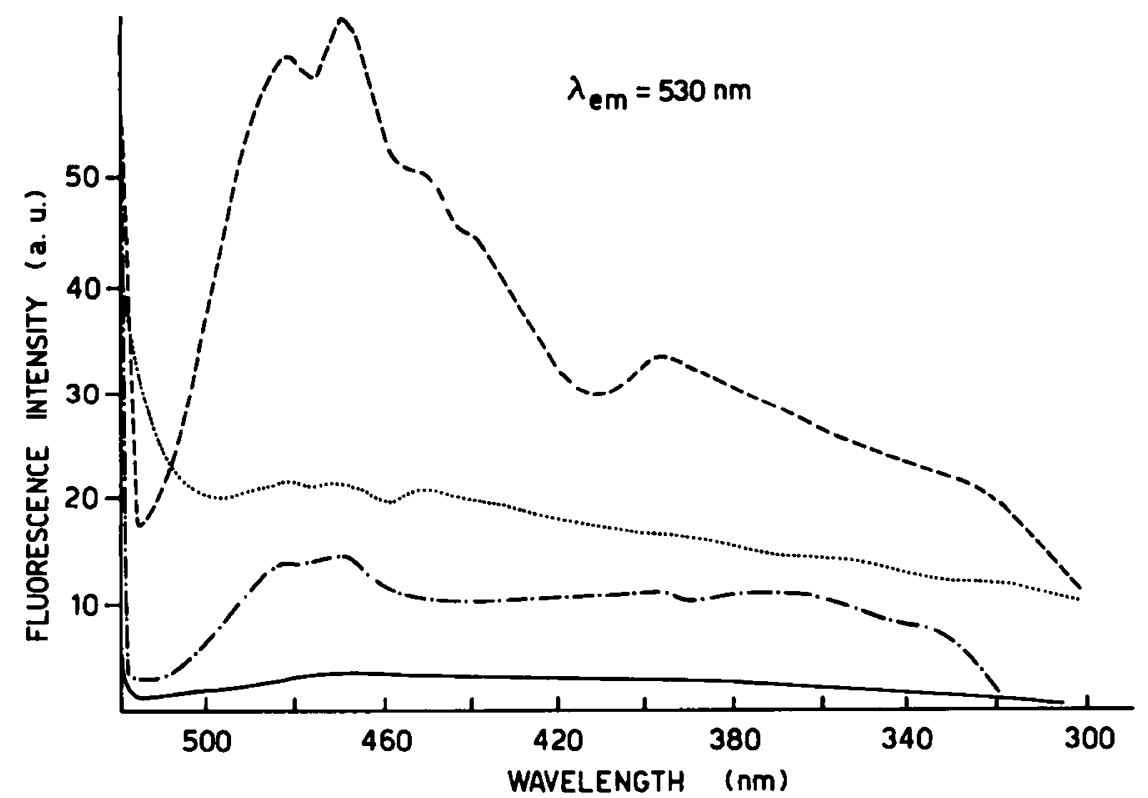

Fig. 1. Fluorescence excitation spectra: whole serum (----), acetone extract (--.-), and acetone-precipitated protein in the presence of $7 \mathbf{M}$ guanidine ( $\longrightarrow$ ). The blood was withdrawn from a jaundiced newborn before phototherapy. The same spectral shape is found after phototreatment for the whole serum and acetone extract. Fluoresence excitation spectrum of acetone-precipitated protein in the presence of $7 \mathrm{M}$ guanidine after phototherapy of the same newborn $(\cdots)$. 
yield of the photoadduct is higher in deoxygenated solutions, it is possible to conceive that the photoprocess does not involve oxidizing agents (e.g., $\left.{ }^{1} \mathrm{O}_{2}\right)$, but occurs through the intermediacy of radical species. A similar mechanism has been proposed (1) for the visible light-induced covalent photoaddition between serum albumin and other dyes.

It has been previously shown (15) that during the initial period of HSA irradiation in the presence of bilirubin two histidyl residues are modified with a concomitant decrease of the protein affinity for bilirubin. The formation of the covalent photoadduct is detected upon irradiation of the complex under the same experimental conditions and for the same period of time. Therefore, it is likely that the two photomodified histidyl residues are located in the albumin peptide 187-397, which selectively contains all the nonremovable bilirubin-type fluorescent material. Consequently, this photochemical approach can be used to identify the high-affinity bilirubin-binding site on the albumin molecule.

The fact that the photoadduct was formed also after in vivo irradiation for 7 to $9 \mathrm{hr}$ with superblue fluorescent lamps indicates that this phenomenon is relevant at the biological level. The high spatial selectivity of the photobinding process as observed in vitro is confirmed in vivo by the specific appearance of the photoadduct in the serum albumin fraction, as well as by the disappearance of the photoadduct over a period of time coincident with the normal albumin turnover.

Until now, no decrease of the serum binding capacity for bilirubin has been observed during phototherapy (2). Instead, it is possible to hypothesize that as a consequence of the photoadduct formation the high-affinity bilirubin-binding site of albumin becomes less available to other substances (free fatty acids, drugs, etc.). The amount of photoaltered albumin is probably low because the photoadduct was barely detectable by absorption spectroscopy studies, i.e., by using an analytical technique less sensitive than spectrophotofluorometry. From the reported data as well as from the review of the literature, we can conclude that until now no photodynamic damage induced by in vivo light treatment has been observed. This fact may be due to the weak photosensitizing efficiency of bilirubin coupled with its high reactivity toward ${ }^{1} \mathrm{O}_{2}$ (11). On the other hand, as mentioned before, the photoprocess involving the serum albumin probably occurs through the intermediacy of radical species (type I mechanism). It is possible that the photodegradation of bilirubin which, with the photoisomerization (10), accounts for the phototherapy-associated decrease of plasma bilirubin, is depending at least in part on the occurrence of type I (radical-involving) processes. Moreover, our findings provide the first precise demonstration of a phototherapy-induced biochemical damage.

Present evidence also shows that some metabolic processes are altered in jaundiced infants treated by phototherapy (14), but until now, there is no evidence that light directly induces these alterations. Nevertheless, we stress the importance to define the doseeffect relationships in phototherapy to avoid overexposure of newborn infants.

\section{REFERENCES AND NOTES}

1. Brandt, J., Fredriksson, M., and Andersson, L. O.: Coupling of dyes to biopolymers by sensitized photooxidation. Affinity labeling of a binding site in bovine serum albumin. Biochemistry, 13: 4758 (1974).

2. Cashore, W. J., Karotkin, E. J., Stern, L., and Oh, W.: The lack of effect of phototherapy on serum bilirubin-binding capacity in newborn infants. $J$. Pediatr., 87: 977 (1975).

3. Chen, R. F.: Removal of fatty acids from serum albumin by charcoal treatment. J. Biol. Chem., 242: 173 (1967).

4. Chen, R. F.: Fluorescence stopped-flow study of relaxation processes in the binding of bilirubin to serum albumins. Arch. Biochem. Biophys., 160: 106 (1974).

5. Chrambach, A., Reisfeld, R. A., Wyckoff, M., and Zaccari, J.: A procedure for rapid and sensitive staining of protein fractionated by polyacrylamide gel electrophoresis. Anal. Biochem.. 20: 150 (1967).

6. Clark, P., Rachinsky, M. R., and Forster, J. F.: Mowing boundary electrophoresis behavior and acid isomerization of human mercaptalbumin. J. Biol. Chem., 237: 2509 (1962).

7. Jacobsen, J.: Studies of the affinity of human serum albumin for binding of bilirubin at different temperatures and ionic strength. Int. J. Peptide Protein Res., 9: 235 (1977)

8. Jori, G., and Spikes, J. D.: Mapping the three-dimensional structure of proteins by photochemical techniques. Photochem. Photobiol. Rev.. 3: 193 (1978).

9. King. T. P., and Spencer, M.: Structural studies and organic ligand-binding properties of bovine plasma albumin. J. Biol. Chem., 245: 6134 (1970).

10. Lightner, D. A.. Woodbridge, T. A., and McDonagh, A. F.: Photobilinubin and early bilirubin photoproduct detected by absorbance difference spectroscopy. Proc. Natl. Acad. Sci. U. S. A., 76: 29 (1979).

11. McDonagh, A. F.: The photochemistry and photometabolism of bilirubin. In: G. B. Odell, R. Schaffer, A. P. Simopoulos: Phototherapy in the newborn: an overview. Pp. 56-73, National Academy of Sciences, Washington, D. C. (1974).

12. McDonagh, A. F., and Assissi, F.: Commercial bilirubin: a trinity of isomers. FEBS Lett., 18: 315 (1962).

13. Moore. S., and Stein, W. M.: Chromatographic determination of amino acids by the use of automatic recording equipment. Methods Enzymol., 6: 819 (1963).

14. Rubaltelli, F. F.: Il neonato ad alto rischio. Itteri gravi a bilirubina indiretta. Minerva Pediatr., 25: 1563 (1973).

15. Rubaltelli, F. F., and Jori, G.: Visible light irradiation of human and bovine serum albumin-bilirubin complex. Photochem. Photobiol., 29: 991 (1979).

16. This paper was presented in part at the 7th Annual Meeting of the American Society for Photobiology, Asilomar, CA. June 1979, and at the Annual Meeting of the European Society for Pediatric Research, Leuven, Belgium, September, 1979.

17. Requests for reprints should be addressed to: Dr. F. F. Rubaltelli, Clinica Pediatrica dell'Università di Padova, Via Giustiniani, 3,35100 Padova, Italy.

18. This research was supported by $C$. N. R. grants 77.01550 .64 and 78.01876 .65 under the U. S. A.-Italy cooperative program in science.

19. Received for publication December 17, 1979.

20. Accepted for publication March 19, 1980. 